\title{
Diamondoid Hydrocarbons as Maturity Indicators for Condensates from Southern Indus Basin, Pakistan
}

\author{
Shagufta Nasir and Tahira Fazeelat \\ Department of Chemistry, University of Engineering \& Technology, G.T. Road, Lahore-54890, Pakistan \\ Correspondence should be addressed to Tahira Fazeelat; fazeelat.tahira@gmail.com
}

Received 13 May 2013; Accepted 5 September 2013

Academic Editor: Alexander Tatarinov

Copyright (C) 2013 S. Nasir and T. Fazeelat. This is an open access article distributed under the Creative Commons Attribution License, which permits unrestricted use, distribution, and reproduction in any medium, provided the original work is properly cited.

\begin{abstract}
Diamondoid hydrocarbons have been examined in condensates reservoired in the Southern Indus Basin using GC-MS. Bulk properties reveal that samples are waxy and low sulfur with the exception of Pakhro and Gopang which are nonwaxy. TIC show bimodal distribution of $n$-alkanes along with high abundance of $\mathrm{C}_{20+} n$-alkanes indicating substantial contribution of terrigeneous $\mathrm{OM}$ in these samples. CPI close to one is consistent with mature nature of oils. The samples show two ranges of $\mathrm{Pr} / \mathrm{Ph}$ ratios. Those within the range of 2.2-2.7 reflect marine depositional settings for OM while others with $\mathrm{Pr} / \mathrm{Ph}>3 \mathrm{may}$ have originated from terrestrial OM deposited under marine oxic conditions. The cross plot of $\mathrm{Pr} / n-\mathrm{C}_{17}$ versus $\mathrm{Ph} / n-\mathrm{C}_{18}$ indicate type III kerogen as main source of OM deposited under marine to marine oxic conditions. The values of diamondoid based maturity parameters, like methyladamantane index 54.1-75.8\% and methyldiamantane index $34.9-56.3 \%$ indicate high level of thermal maturity corresponding to vitrinite reflectance 1.1-1.6\%. No biodegradation is observed in any of these samples as shown by methyladamantanes/adamantane 3.99-5.52 and methyldiamantanes/diamantane 2.16-2.99 and supported by high values of API gravity $\left(45.13^{\circ}-60.02^{\circ}\right)$ and absence of UCM.
\end{abstract}

\section{Introduction}

Diamondoids are a group of three-dimensional cyclohexane ring alkanes that have highly symmetrical and strain-free diamond like fused ring structures in chair conformation (Figure 1) [1-3]. This name originated from the word "adames," the Greek letter for diamond, after the discovery of these compounds from Czechoslovakian petroleum [4]. The simplest of these polycyclic diamondoids is adamantane followed by its homologues diamantanes, trimantanes, tetramantanes, pentamantanes, and hexamantanes [5]. Diamondoids in petroleum and sediment extracts are extremely stable compounds. These are generally more stable than any other hydrocarbon class in geological samples, hence more resistant to alteration processes like biodegradation and maturation $[3,5-11]$. Because of these properties diamondoids have been used in evaluating geochemistry of source rocks and crude oils including biodegradation and thermal maturity of high maturity crude oils and condensates [9-14]. Sassen and Post used $\delta^{13} \mathrm{C}$ values of diamondoids for establishing oil to source correlation of condensates [15]. Jalees et al. used diamondoids and biomarkers to study the effect of maturity and biodegradation on crude oils and condensates [16]. Dahl et al. proposed diamondoid hydrocarbons as indicators of oil cracking [12]. Others researchers used methyladamantane and methyldiamantane indices as maturity parameters for high maturity oils $[9,16,17]$. The most commonly used technique to analyze diamondoids is gas chromatographymass spectrometry (GC-MS). Recently, Liang et al. used GCMS-MS and Li et al. used two-dimensional gas chromatography with time of flight mass spectroscopy (GC $\times$ GCTOFMS) for identification and characterization of diamondoids in condensates $[18,19]$. These techniques enabled these authors to identify di- and tri-methyladamantanes more effectively.

In this study we have used diamondoids along with $n$ alkanes and isoprenoid parameters to evaluate geochemistry and thermal maturity of condensates from the Southern Indus Basin which is difficult to find otherwise because of extremely low concentration of biomarkers in these samples. 
TABLE 1: Geological and bulk properties of the condensate samples.

\begin{tabular}{|c|c|c|c|c|c|c|c|c|c|c|c|c|}
\hline \multirow{2}{*}{$\begin{array}{l}\text { Sr. } \\
\text { number }\end{array}$} & \multirow{2}{*}{ Sample name } & \multirow{2}{*}{ Depth $(\mathrm{ft})^{1}$} & \multicolumn{2}{|c|}{ Reservoir formation $^{1}$} & \multirow{2}{*}{${ }^{\circ} \mathrm{API}$} & \multirow{2}{*}{$\% S$} & \multirow{2}{*}{$\mathrm{PP}\left({ }^{\circ} \mathrm{C}\right)$} & \multirow{2}{*}{ Waxy/nonwaxy } & \multirow{2}{*}{ CPI } & \multirow{2}{*}{$\mathrm{Pr} / \mathrm{Ph}$} & \multirow{2}{*}{$\mathrm{Pr} / n-\mathrm{C}_{17}$} & \multirow{2}{*}{$\mathrm{Ph} / n-\mathrm{C}_{18}$} \\
\hline & & & Name & Age & & & & & & & & \\
\hline 1 & Resham & NA & NA & NA & 45.13 & $<0.1$ & 1 & Waxy & 1.05 & 2.77 & 0.21 & 0.08 \\
\hline 2 & Dhamrakhi & 8142 & L. Goru & Cretaceous & 47.59 & $<0.1$ & 4 & II & 1.05 & 4.46 & 0.28 & 0.07 \\
\hline 3 & Baloch & 5744 & L. Goru MS & Cretaceous & 50.37 & $<0.1$ & 4 & $\prime \prime$ & 1.02 & 2.17 & 0.19 & 0.08 \\
\hline 4 & Unnar & NA & L. Goru MS & Cretaceous & 48 & $<0.1$ & 1 & 11 & 1.05 & 2.46 & 0.17 & 0.09 \\
\hline 5 & Shah & 9849 & L. Goru MS & Cretaceous & 47.54 & $<0.1$ & 3 & 11 & 1.01 & 2.50 & 0.21 & 0.09 \\
\hline 6 & Pasahki East & NA & L. Goru MS & Cretaceous & 46.19 & $<0.1$ & 4 & $\prime \prime$ & 1.04 & 2.58 & 0.19 & 0.08 \\
\hline 7 & Pakhro & 10515 & L. Goru BS & Cretaceous & 55 & $<0.1$ & $<-10$ & Nonwaxy & 0.93 & 1.94 & 0.11 & 0.04 \\
\hline 8 & Gopang & NA & NA & NA & 60.02 & $<0.1$ & $<-10$ & 11 & 0.84 & 4.49 & 0.34 & 0.11 \\
\hline
\end{tabular}

${ }^{1}$ Data from Oil and Gas Development Corporation Limited (OGDCL); CPI: $2\left(\mathrm{C}_{23}+\mathrm{C}_{25}+\mathrm{C}_{27}+\mathrm{C}_{29}\right) /\left[\mathrm{C}_{22}+2 *\left(\mathrm{C}_{24}+\mathrm{C}_{26}+\mathrm{C}_{28}\right)+\mathrm{C}_{30}[29]\right.$; waxy and nonwaxy on the basis of PP $\geq 1$ and $<1$; L. Goru MS: lower Goru massive sand; L. Goru BS: lower Goru basal sand; NA: not available.

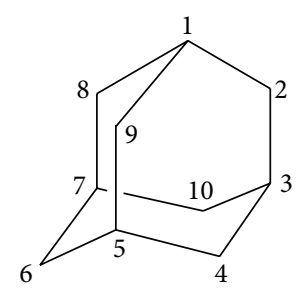

(I)

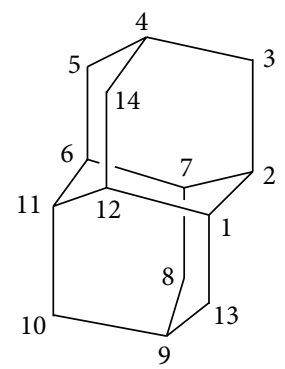

(II)
FIGURE 1: Structure and numbering of adamantane (I) and diamantane (II).

\section{Experimental}

2.1. Samples Details. Eight condensates samples collected from different oil fields of the Southern Indus Basin were analyzed in this study. The location of sample wells is shown in Figure 2, while geological information is listed in Table 1. A brief geological description of the study area is outlined below and described in more detail by Wandrey et al. [20]. The basin is bounded to the north by the Middle Indus Basin, to the northwest by the Sulaiman Fold Belt, and the Kirthar Fold Belt in the southwest (Figure 2). The hydrocarbon expulsion, migration, and entrapment occurred mainly during Eocene to Miocene time. Source rocks have been identified in Cretaceous and Eocene successions. The Early Cretaceous shales of Sembar and Goru Formations have been recognized as source for the bulk of hydrocarbons charging several oil and gas fields in the Southern Indus Basin. Sembar shales contain mixed type II and type III kerogen and are thought to be deposited under shallow marine depositional conditions [21]. Upper Cretaceous Goru sands and Eocene carbonates are the main reservoirs in the Southern Indus Basin [2023]. The condensate samples used in this study belong to the Cretaceous reservoirs of Lower Goru Formation.
2.2. Physiochemical Analysis. API gravity, pour point, and sulfur content were determined using ASTM methods [2426]. Details are described elsewhere [27].

2.3. Separation of Compound Classes by Liquid Chromatography. Condensate samples were fractionated into saturates, aromatics, and polar fractions using liquid column chromatography employing a standard method described elsewhere [28]. In brief, sample (30 mg) dissolved in $n$-hexane $(500 \mu \mathrm{L})$ was introduced onto the top of activated silica gel column that has been activated at $250^{\circ} \mathrm{C}$ for overnight. Saturated hydrocarbon fractions were eluted with three bed volumes of $n$-hexane, aromatic fractions with three bed volumes of mixture of $n$-hexane: dichloromethane $(9: 1)$, and the polars with three bed volumes of $1: 1$ mixture of dichloromethane and methanol. Saturated fractions were analysed by gas chromatography-mass spectrometry (GCMS).

2.4. Gas Chromatography-Mass Spectrometry. GC-MS analysis was performed using a Hewlett-Packard (HP) 5973 Mass Selective Detector Interfaced to a HP6890 gas chromatograph, which was fitted with a DB-5 capillary column (J and $\mathrm{W}$ Scientific, $60 \mathrm{~m}, 0.25 \mathrm{~mm}$ internal diameter, $0.25 \mu \mathrm{m})$. The GC oven was programmed from $40^{\circ} \mathrm{C}$ to $310^{\circ} \mathrm{C}$ at a heating rate of $3^{\circ} \mathrm{C} / \mathrm{min}$ with initial and final hold times of 1 and 30 minutes, respectively. The MS source and quadruple temperatures were at $230^{\circ} \mathrm{C}$ and $106^{\circ} \mathrm{C}$, respectively. Samples were dissolved in $n$-hexane and injected in a pulsed splitless mode using an autosampler. Helium was used as the carrier gas at a linear velocity of $27 \mathrm{~cm} / \mathrm{s}$ with the injector operating at constant flow. The MS was operating with ionization energy $70 \mathrm{eV}$, source temperature $180^{\circ} \mathrm{C}$, and electron multiplier voltage $1800 \mathrm{~V}$. Data was acquired in a full scan mode from mass range of 50 to $550 \mathrm{amu}$.

\section{Results and Discussion}

3.1. Bulk Properties. The crude oils are classified as heavy, medium, and light on the basis of API gravity values $\leq 20^{\circ}$, 


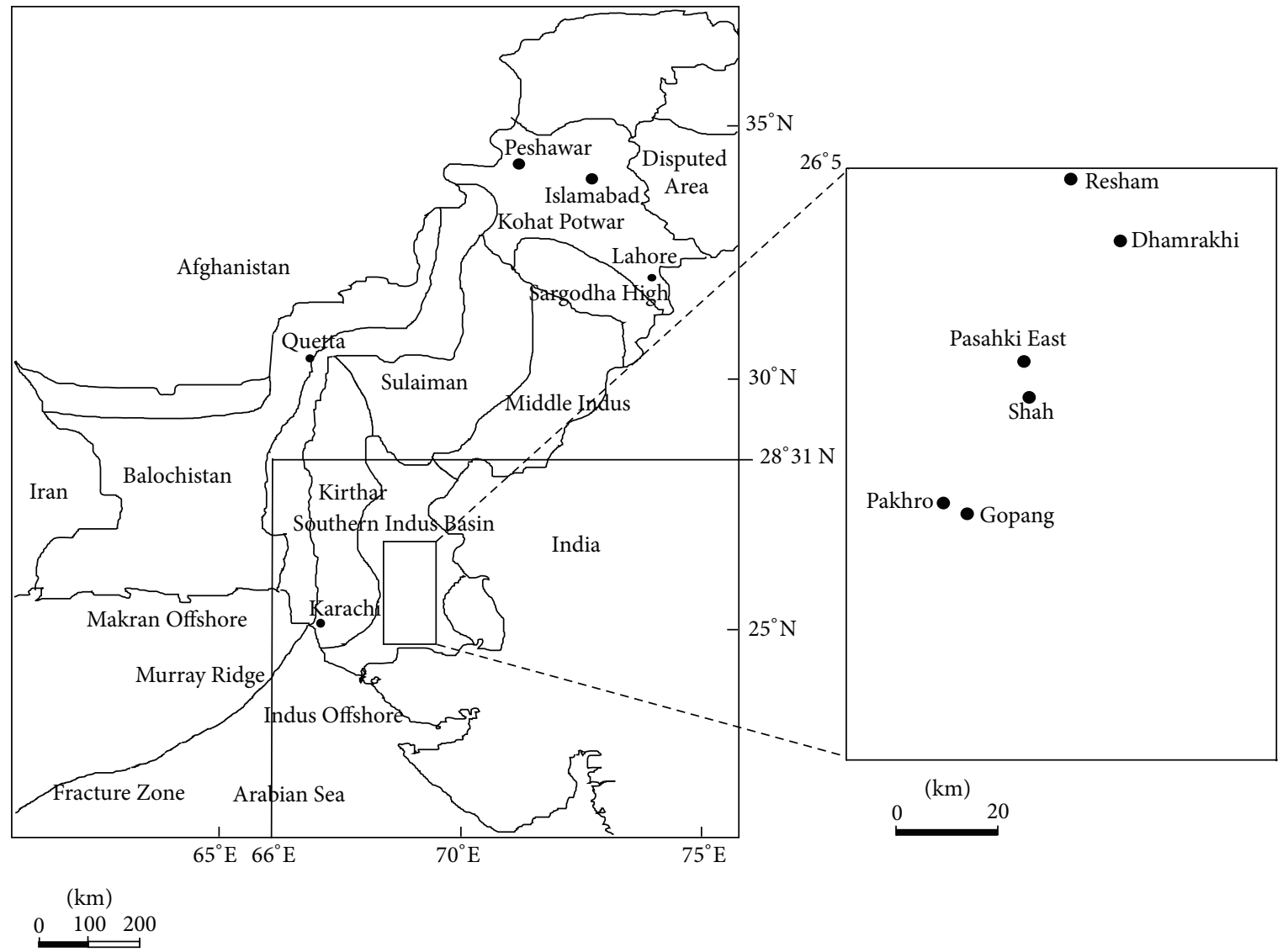

FIGURE 2: Map showing location of condensates wells within the Southern Indus Basin.

$20-40^{\circ}$, and $40-45^{\circ}$, respectively, while condensates have API gravity values $>45^{\circ}$ [29]. The samples analyzed in this study have API gravity values between 46 and $60^{\circ}$ (Table 1) and are classified as condensates.

Pour point $(\mathrm{PP})$ is generally associated with paraffinicity or waxy nature of crude oils. The term high paraffinic reflects high concentration of $\mathrm{C}_{20+} n$-alkanes in petroleum. Crude oils derived from terrigenous OM generally have high paraffinic content and high PP. Figure 3 and data listed in Table 1 show that the analyzed samples having high concentration of $\mathrm{C}_{20+} n$-alkanes have high values of PP up to $4^{\circ} \mathrm{C}$ and are waxy in nature, so all the samples except Pakhro and Gopang are waxy condensates, while those having low concentration of $\mathrm{C}_{20+} n$-alkanes show low PP and are nonwaxy in nature, for example, Pakhro and Gopang.

Sulfur compounds are undesirable in crude oils and its products because of extra cost incurred on sulfur removal and environmental problems associated with sulfur compounds. The crude oils are termed as sour or sweet on the basis of sulfur content $>1 \%$ and $<1 \%$. The sulfur content of analyzed samples is extremely low $(<0.1 \%)$ rendering these samples as sweet and commercially valuable.

3.2. n-Alkanes and Isoprenoids Distributions. The distribution pattern of $n$-alkanes provides useful information on the source of OM, thermal maturity, and biodegradation.
Total ion gas chromatograms of waxy condensates described above show bimodal distribution of $n$-alkanes (Figure 3), thereby reflecting that source generating these oils has high contribution of terrestrial OM. The absence of UCM indicates that the samples have not undergone biodegradation. Carbon preference index (CPI) of samples is close to one indicating that these samples are high maturity condensates [30] (Table 1). Oil derived from terrigenous OM show marked predominance of $\mathrm{C}_{27}, \mathrm{C}_{29}$, and $\mathrm{C}_{31} n$-alkanes which is lost at high maturity level. The analyzed samples do not show odd or even predominance of $n$-alkanes and exhibit uniform distribution. This feature is attributed to high thermal maturity of these samples.

Pristane to phytane $(\mathrm{Pr} / \mathrm{Ph})$ ratios in crude oil and source rocks within oil window reflect redox potential in the depositional environment and nature of OM [31]. Most marine and organic rich sediments have $\mathrm{Pr} / \mathrm{Ph}$ ratios in the range of $0.8-$ 2.5 , which show a gradual increase with increasing maturity within this range, although marine $\mathrm{OM}$ usually has $\mathrm{Pr} / \mathrm{Ph}$ ratio $<1.5$ at high maturity levels, while terrigenous $\mathrm{OM}$ input under oxic conditions shows ratios $>3$ [29]. Lower values $(<0.8)$ typify anoxic commonly hypersaline or carbonate environment, particularly if it is accompanied by high sulfur content [32-34]. Pr/Ph ratios of six samples (Sr. number 16) are 2.2 to 2.77 and indicate significant contribution from terrigenous $\mathrm{OM}$ input under marine depositional settings. 

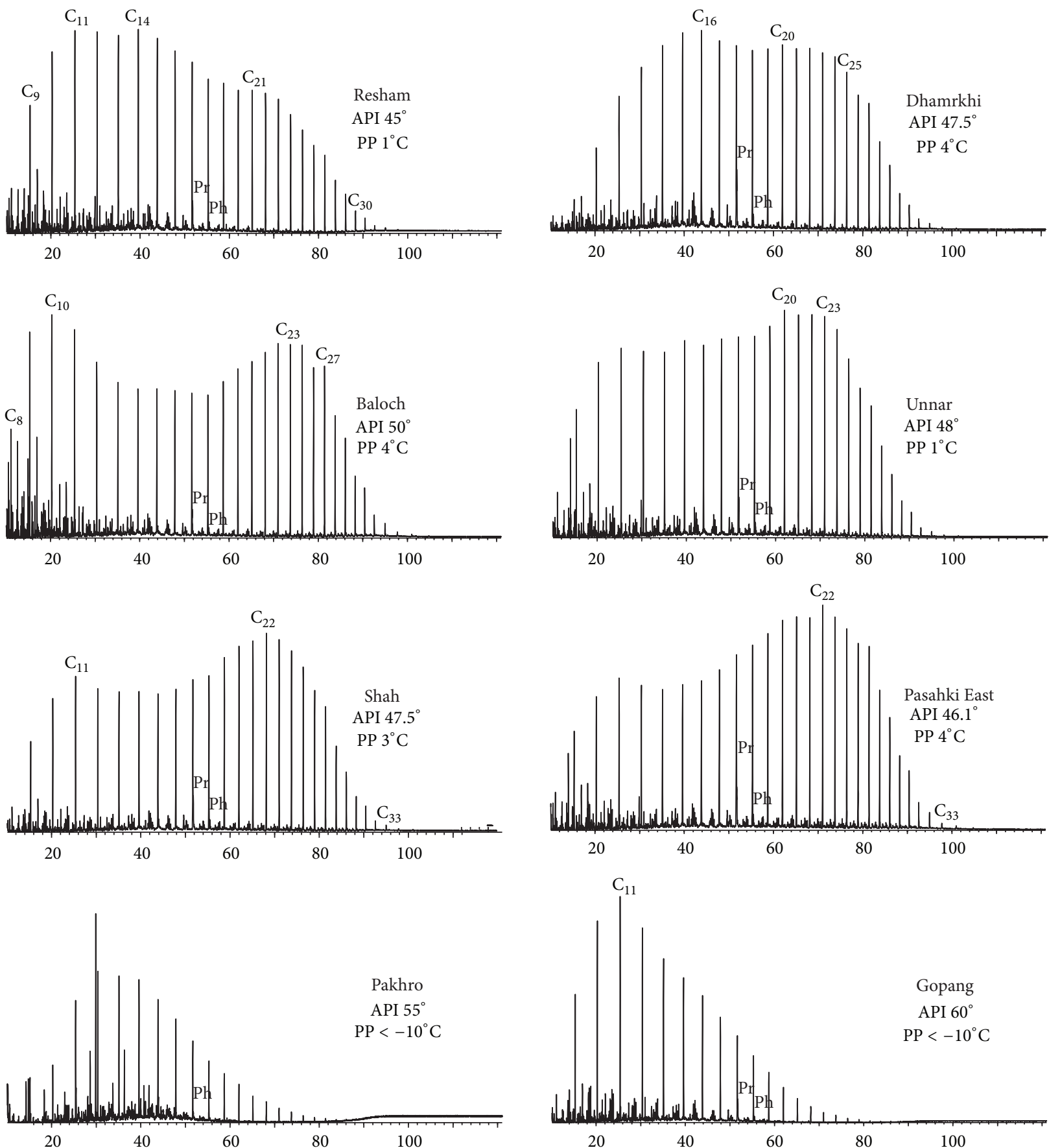

20

40

FIGURE 3: Total ion chromatograms from GC-MS analysis showing distribution of $n$-alkanes and isoprenoids ( $\mathrm{Pr}$ and $\mathrm{Ph}$ ) in condensates from the Southern Indus Basin. $\mathrm{C}_{8}-\mathrm{C}_{33}$ represents $n$-alkanes with carbon atoms $8-33$. $\mathrm{Pr}$ and $\mathrm{Ph}=\mathrm{Pristane}(\mathrm{Ph})$ and $\mathrm{Phytane}(\mathrm{Ph})$ are $\mathrm{C}_{19}$ and $\mathrm{C}_{20}$ regular acyclic isoprenoids which elute after $\mathrm{C}_{17}$ and $\mathrm{C}_{18} n$-alkanes.

Higher value of 3.95 has been observed for Gopang, which is $60^{\circ} \mathrm{API}$ and $<-10^{\circ} \mathrm{C} \mathrm{PP}$ condensate, and high value of $\mathrm{Pr} / \mathrm{Ph}$ reflects very high thermal maturity as well as substantial contribution from terrigenous source of OM input under oxic conditions for this sample. Similarly high $\mathrm{Pr} / \mathrm{Ph}$ ratio (3.98) for Dhamrkhi is consistent with an origin from source rocks having substantial contribution of terrestrial $\mathrm{OM}$ and deposited under marine oxic conditions.
The $\mathrm{Pr} / n-\mathrm{C}_{17}$ ratios have been used to differentiate OM under swamp environment $(<1.5)$ from those found under marine environments $(<0.5)$ although this ratio is affected by maturity [35-37]. The $\mathrm{Pr} / n-\mathrm{C}_{17}$ ratios of analyzed samples are in a close range of $0.11-0.34$ and indicate marine depositional conditions of OM. The $\mathrm{Pr} / n-\mathrm{C}_{17}$ versus $\mathrm{Ph} / n-\mathrm{C}_{18}$ plot proposed by Shanmugam provides useful information regarding thermal maturity, biodegradation, 


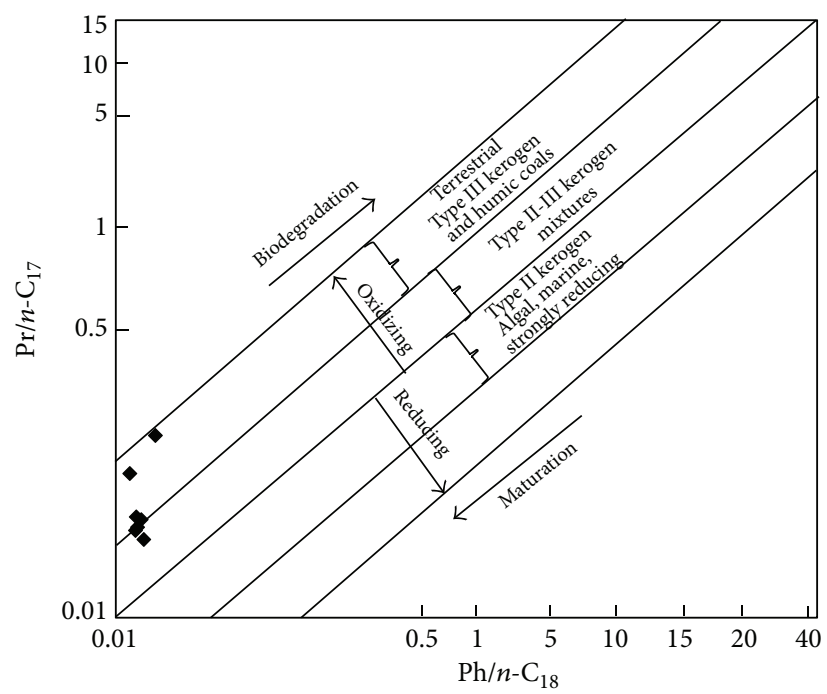

Figure 4: $\mathrm{Pr} / n-\mathrm{C}_{17}$ versus $\mathrm{Ph} / n-\mathrm{C}_{18}$ plot showing high maturity and substantial contribution of type III organic matter in source rocks of these samples.
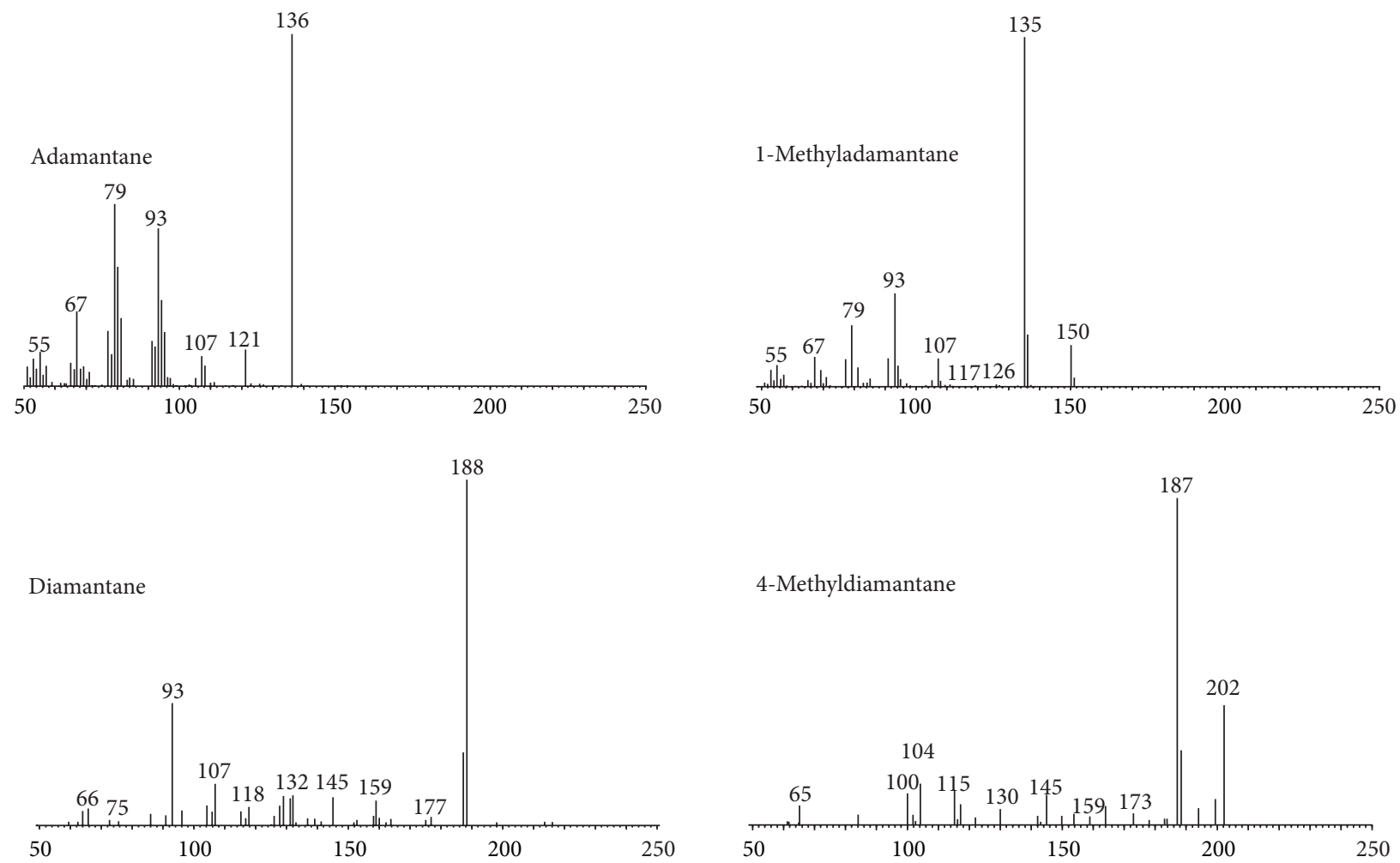

FiguRE 5: Mass spectra of peaks 1, 5, 18, and 23 (Figure 6) assigned as 1-methyladamantane, adamantane, 4-methyldiamantane, and diamantine on the basis of the literature data $[9,10]$.

and depositional conditions of OM [35]. Increased thermal maturity results in decreased isoprenoid/n-alkane ratio due to fast release of $n$-alkanes compared to isoprenoids. On the other hand biodegradation results in increased isoprenoid/ $n$-alkane ratios due to fast removal of $n$-alkanes prior to isoprenoids. The Southern Indus Basin condensates show extremely low values of $\mathrm{Pr} / n-\mathrm{C}_{17}$ and $\mathrm{Ph} / n-\mathrm{C}_{18}$ in the range of $0.11-0.34$ and $0.04-0.11$, respectively (Table 1). The samples have gathered towards the lower left corner of the plot suggesting high thermal maturity for the samples (Figure 4). The source of OM is mainly type III kerogen deposited under marine oxic conditions which is likely to generate waxy oils or condensates under high thermal conditions. 

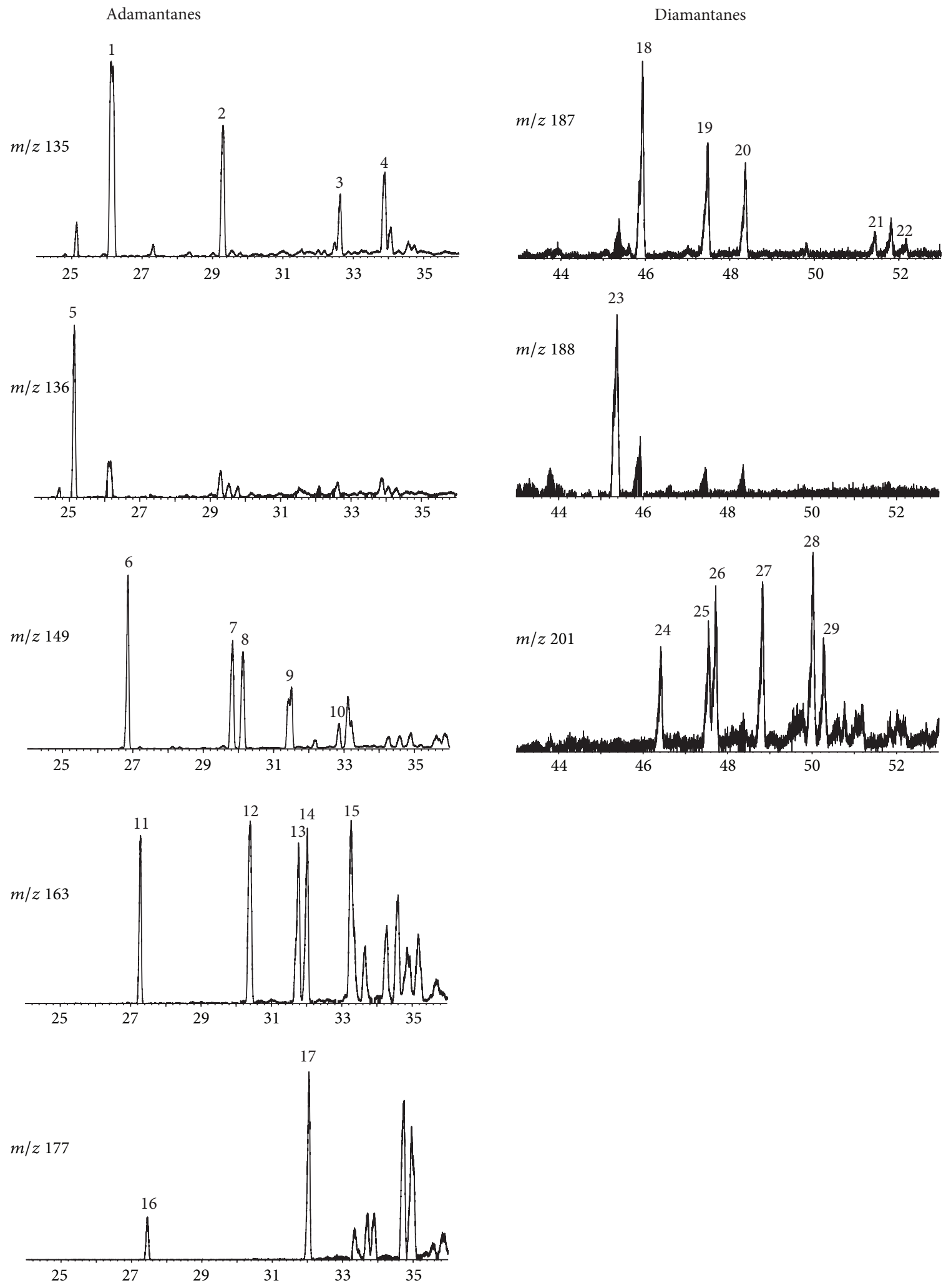

Figure 6: Single ion chromatograms $m / z$ 135, 136, 149, and 163 and $177 \mathrm{~m} / z$ 187, 188, and 201 showing distribution and elution order of adamantanes and diamantanes in a representative condensate sample (Gopang). Refer to Table 2 for identity of peaks. 
TABLE 2: Diamondoid hydrocarbons identified in Southern Indus Basin condensates.

\begin{tabular}{|c|c|c|c|c|c|}
\hline $\begin{array}{l}\text { Peak } \\
\text { number }\end{array}$ & Compound & Abbreviation & $\begin{array}{c}\text { Molecular } \\
\text { formula }\end{array}$ & $\begin{array}{c}\text { Base peak } \\
(m / z)\end{array}$ & $\begin{array}{c}\mathrm{M}^{+} \\
(m / z)\end{array}$ \\
\hline 1 & 1-Methyladamantane & 1-MA & $\mathrm{C}_{11} \mathrm{H}_{18}$ & 135 & 150 \\
\hline 2 & 2-Methyladamantane & 2-MA & $\mathrm{C}_{11} \mathrm{H}_{18}$ & 135 & 150 \\
\hline 3 & 1-Ethyladamantane & 1-EtA & $\mathrm{C}_{12} \mathrm{H}_{20}$ & 135 & 164 \\
\hline 4 & 2-Ethyladamantane & 2-EtA & $\mathrm{C}_{12} \mathrm{H}_{20}$ & 135 & 164 \\
\hline 5 & Adamantane & A & $\mathrm{C}_{10} \mathrm{H}_{16}$ & 136 & 136 \\
\hline 6 & 1,3-Dimethyladamantane & 1,3-DMA & $\mathrm{C}_{12} \mathrm{H}_{20}$ & 149 & 164 \\
\hline 7 & 1,4-Dimethyladamantane (cis) & 1,4-DMA & $\mathrm{C}_{12} \mathrm{H}_{20}$ & 149 & 164 \\
\hline 8 & 1,4-Dimethyladamantane (trans) & 1,4-DMA & $\mathrm{C}_{12} \mathrm{H}_{20}$ & 149 & 164 \\
\hline 9 & 1,2-Dimethyladamantane & 1,2-DMA & $\mathrm{C}_{12} \mathrm{H}_{20}$ & 149 & 164 \\
\hline 10 & 2,6-Dimethyladamantane $+2,4$-dimethyladamantan & $2,6-\mathrm{DMA}+2,4-\mathrm{DMA}$ & $\mathrm{C}_{12} \mathrm{H}_{20}$ & 149 & 164 \\
\hline 11 & 1,3,5-Trimethladamantane & 1,3,5-TMA & $\mathrm{C}_{13} \mathrm{H}_{22}$ & 163 & 178 \\
\hline 12 & 1,3,6-Trimethladamantane & $1,3,6-\mathrm{TMA}$ & $\mathrm{C}_{13} \mathrm{H}_{22}$ & 163 & 178 \\
\hline 13 & 1,3,4-Trimethladamantane (cis) & $1,3,4-\mathrm{TMA}$ & $\mathrm{C}_{13} \mathrm{H}_{22}$ & 163 & 178 \\
\hline 14 & 1,3,4-Trimethladamantane (trans) & 1,3,4-TMA & $\mathrm{C}_{13} \mathrm{H}_{22}$ & 163 & 178 \\
\hline 15 & 1-Ethyl, 3,5-dimethyladamantane & 1-Et, 3,5-DMA & $\mathrm{C}_{14} \mathrm{H}_{24}$ & 163 & 192 \\
\hline 16 & 1,3,5,7-Tetramethyladamantane & 1,3,5,7-ТeMA & $\mathrm{C}_{14} \mathrm{H}_{24}$ & 177 & 192 \\
\hline 17 & 1,2,5,7-Tetramethyladamantane & 12,5,7-ТeMA & $\mathrm{C}_{14} \mathrm{H}_{24}$ & 177 & 192 \\
\hline 18 & 4-Methyldiamantane & 4-MD & $\mathrm{C}_{15} \mathrm{H}_{22}$ & 187 & 202 \\
\hline 19 & 1-Methyldiamantane & $1-\mathrm{MD}$ & $\mathrm{C}_{15} \mathrm{H}_{22}$ & 187 & 202 \\
\hline 20 & 3-Methyldiamantane & 3-MD & $\mathrm{C}_{15} \mathrm{H}_{22}$ & 187 & 202 \\
\hline 21 & 1-Ethyldiamantane & $1-\mathrm{EtD}$ & $\mathrm{C}_{16} \mathrm{H}_{24}$ & 187 & 216 \\
\hline 22 & 2-Ethyldiamantane & $2-\mathrm{EtD}$ & $\mathrm{C}_{16} \mathrm{H}_{24}$ & 187 & 216 \\
\hline 23 & Diamantane & $\mathrm{D}$ & $\mathrm{C}_{14} \mathrm{H}_{20}$ & 188 & 188 \\
\hline 24 & 4,9-Dimethyldiamantane & 4,9-DMD & $\mathrm{C}_{16} \mathrm{H}_{24}$ & 201 & 216 \\
\hline 25 & 1,2-Dimethyldiamantane + 2,4-dimethyldiamantane & 1,2-DMD + 2,4-DMD & $\mathrm{C}_{16} \mathrm{H}_{24}$ & 201 & 216 \\
\hline 26 & 4,8-Dimethyldiamantane & 4,8-DMD & $\mathrm{C}_{16} \mathrm{H}_{24}$ & 201 & 216 \\
\hline 27 & 3,4-Dimethyldiamantane & 3,4-DMD & $\mathrm{C}_{16} \mathrm{H}_{24}$ & 201 & 216 \\
\hline 28 & Dimethyldiamantane 1 & ${ }^{*} \mathrm{NI}$ & $\mathrm{C}_{16} \mathrm{H}_{24}$ & 201 & 216 \\
\hline 29 & Dimethyldiamantane 2 & ${ }^{*} \mathrm{NI}$ & $\mathrm{C}_{16} \mathrm{H}_{24}$ & 201 & 216 \\
\hline
\end{tabular}

${ }^{*}$ NI: not identified.

3.3. Assignment of Diamondoid Hydrocarbons. Diamondoids in the condensate samples have been analyzed and identified by GC-MS. These compounds were identified by comparing their mass spectra and relative retention time (Figures 5 and $6)$ with the previous studies $[2,3,9-11,13,38]$. The structure and numbering of adamantane and diamantane are shown in Figure 1. Adamantanes and diamantanes were examined using $m / z 135,136,149,163$, and 177 and $m / z$ 187, 188, and 201, respectively. Figure 6 shows the distribution and elution order of adamantanes and diamantanes in a representative sample, while Table 2 enlists identity and mass spectral properties of different isomers.

3.4. Diamondoid Hydrocarbons as Indicators of Thermal Maturity. Diamondoids are highly stable compounds under thermal conditions. Therefore these compounds have been used to estimate thermal maturity of highly mature samples including condensates $[9,10,13]$. The use of diamondoid hydrocarbons as maturity indicator is based on the relative stability of different isomers under different thermal conditions. For example, 1-methyladamantane (1-MA) is thermally more stable than 2-methyladamantane (2-MA) due to methyl at bridgehead and tertiary position in the former, and hence its concentration increases with maturity. Similarly 4-methyldiamantane (4-MD) is more stable compared to 1-methyldiamantane (1-MD) and 3-methyldiamantane (3$\mathrm{MD})$. Chen et al. introduced methyladamantane index (MAI) and methyldiamantane index (MDI) to distinguish different maturity levels $[9,10]$. They proposed that samples of vitrinite reflectance $\left(R_{o}\right) 1.1-1.3 \%$ have MAI values between 50 and $70 \%$ and MDI values between 30 and $40 \%$. Similarly samples with $R_{o}$ values $1.3-1.6 \%$ were shown to have MAI $70-80 \%$ and MDI $40-50 \%$, while those with $R_{o}$ values $1.6-1.9 \%$ showed MAI $80-90 \%$ and MDI 50-60\%. Samples of even higher maturities $\left(R_{o}>1.9\right)$ have MAI $>90 \%$ and MDI $>60 \%$ $[9,10]$. The values of indices MAI and MDI thus provide 
TABle 3: Parameters based on diamondoid hydrocarbons.

\begin{tabular}{|c|c|c|c|c|c|}
\hline Sr. number & Name of oil & MAI\% & MDI\% & $\mathrm{MA} / \mathrm{A}$ & $\mathrm{MD} / \mathrm{D}$ \\
\hline 1 & Resham & 60.8 & 37.3 & 4.91 & 2.99 \\
\hline 2 & Dhamrakhi & 58.7 & 34.9 & 4.87 & 2.65 \\
\hline 3 & Baloch & 64.8 & 41.8 & 4.57 & 2.55 \\
\hline 4 & Unnar & 54.1 & 48.4 & 3.99 & 2.16 \\
\hline 5 & Shah & 65.2 & 40.7 & 4.51 & 2.43 \\
\hline 6 & Pasahki East & 70.9 & 40.4 & 4.82 & 2.55 \\
\hline 7 & Pakhro & 75.8 & 52.0 & 5.52 & 2.35 \\
\hline 8 & Gopang & 64.1 & 56.3 & 4.49 & 2.22 \\
\hline
\end{tabular}

$\mathrm{MAI} \%=(1-\mathrm{MA} / 1-\mathrm{MA}+2-\mathrm{MA}) * 100[9,10] ; \mathrm{MDI} \%=(4-\mathrm{MD} / 1-\mathrm{MD}+3-\mathrm{MD}+4-\mathrm{MD}) * 100[9,10] ; \mathrm{MA} / \mathrm{A}=1-\mathrm{MA}+2-\mathrm{MA} / \mathrm{A}[11] ; \mathrm{MD} / \mathrm{D}=1-\mathrm{MD}+3-\mathrm{MD}+4-$ MD/DIA [11].

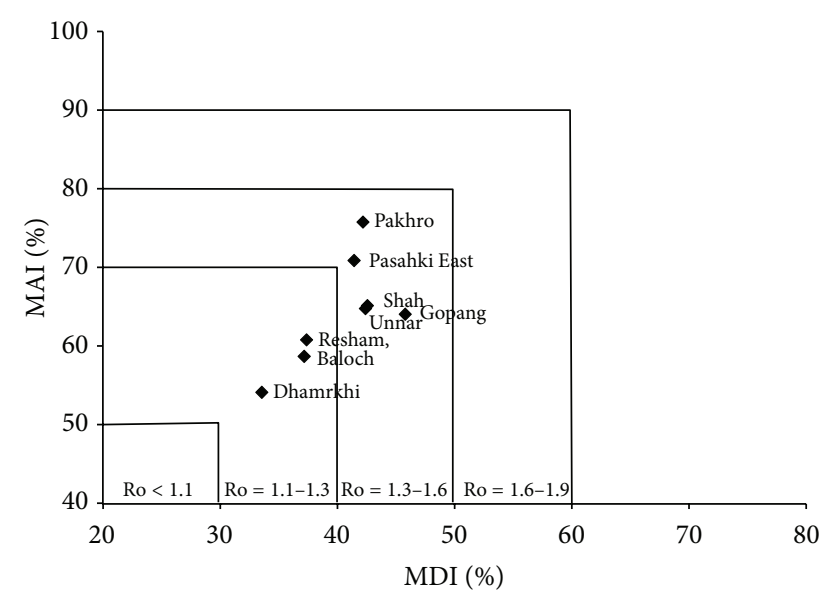

Figure 7: Cross-plot of MAI\% and MDI\% for Southern Indus Basin condensates showing high thermal maturity corresponding to $R_{o}$ 1.1-1.3 for Resham, Baloch, and Dhamrkhi and $R_{o} 1.3-1.6$ for Unnar, Shah, Gopang, Pasahki East, and Pakhro $[9,10]$.

guidelines for maturity determination particularly for high maturity samples including condensates. The distribution and relative abundances of adamantane, methyladamantanes, diamantine, and methyldiamantanes in a representative sample (Gopang) are shown in Figure 6, while values of MAI and MDI are listed in Table 3. Among the samples suit Dhamrkhi with MAI $58.7 \%$ and MDI $34.9 \%$ is the least mature and Pakhro with MAI $75.8 \%$ and MDI 52\% is the most mature (Table 3). Cross-plot of MAI and MDI is shown in Figure 7 which indicates that the Southern Indus Basin condensates, Resham, Baloch, and Dhamrkhi, with MAI 58.7-64.8\% and MDI 34.9-41.8\%, have thermal maturities equivalent to $R_{o}$ 1.1-1.3 and Unnar, Shah, Gopang, Pasahki East, and Pakhro, with MAI 54.1-75.8\% and MDI 40.4-56.3\%, have higher maturities corresponding to reflectance range 1.3-1.6.

3.5. Biodegradation. Diamondoids are highly resistant to biodegradation. The stability of these compounds allows to use these compounds as fingerprints for the assessment of biodegradation. The ratios methyladamantanes/adamantane (MA/A) and methyldiamantanes/diamantane (MD/D) have been applied to assess biodegradation of crude oil [11]. Higher values of MA/A up to 16 indicate progressive level of microbial activity and in-reservoir biodegradation. MA/A is sensitive to even initial stages of biodegradation, and values $>6.3$ have been observed for slightly biodegraded oils. However the value increases with progressive increase in level of biodegradation. On the other hand $\mathrm{MD} / \mathrm{D}$ values are not affected by slight to moderate biodegradation; however slight change in $\mathrm{MD} / \mathrm{D}$ ratio $(>3.5)$ has been observed at severe levels of biodegradation (level 8) [11]. The values of MA/A and $\mathrm{MD} / \mathrm{D}$ for the analyzed samples are listed in Table 2 which range from 3.99 to 5.52 and 2.16 to 2.99 , respectively. These values are lower than the limits described for biodegradation suggesting that no biodegradation has taken place in the Southern Indus Basin condensates. Moreover, $n$-alkanes profile and absence of UCM also support nonbiodegraded nature of these samples.

\section{Conclusions}

(i) Bulk properties of samples reveal that six samples ( $\mathrm{Sr}$. no. 1-6) with API gravity $45-50^{\circ}$ and $\mathrm{PP} 1-4^{\circ} \mathrm{C}$ are waxy condensates, while two (Sr. no. 7-8) with API 55 and 60 and $\mathrm{PP}<-10^{\circ} \mathrm{C}$ are nonwaxy condensates.

(ii) Bimodal distribution of $n$-alkanes and high abundance of $\mathrm{C}_{20+} n$-alkanes suggests terrigenous source of $\mathrm{OM}$ for the condensates, while $\mathrm{Pr} / \mathrm{Ph}$ ratios 2.22.77 and $3.95-3.98$ suggest marine to marine oxic environment of deposition for the samples.

(iii) Isoprenoid $/ n$-alkane ratios and $\operatorname{Pr} / n$ - $\mathrm{C}_{17}$ versus $\mathrm{Ph} / n$ $\mathrm{C}_{18}$ plot suggest marine to marine oxic depositional conditions and type III kerogen as main source of OM which is likely to generate waxy oils or condensates under high thermal conditions.

(iv) Diamondoid-based maturity parameters (MAI and MDI) have indicated that samples have attained high levels of thermal maturity corresponding to vitrinite reflectance $1.1-1.6 \%$

(v) Absence of UCM and ratios of MA/A and MD/D indicate that samples are nonbiodegraded. 


\section{Abbreviations}

$\begin{array}{ll}\text { A: } & \text { Adamantane } \\ \text { MA: } & \text { Methyladamantane } \\ \text { D: } & \text { Diamantane } \\ \text { MD: } & \text { Methyldiamantane } \\ \text { MAI: } & \text { Methyladamantane index } \\ \text { MDI: } & \text { Methyldiamantane index } \\ \text { PP: } & \text { Pour point } \\ \text { CPI: } & \text { Carbon preference index } \\ \text { OM: } & \text { Organic matter } \\ \text { UCM: } & \text { Unresolved complex mixture } \\ \text { GC-MS: } & \text { Gas chromatography-mass spectrometry. }\end{array}$

\section{Acknowledgment}

The authors are thankful to Oil and Gas Development Company Limited (OGDCL), Pakistan, for providing the condensate samples and geological data.

\section{References}

[1] R. C. Fort, Adamantane: The Chemistry of Diamond Molecules, Marcel Dekker, New York, NY, USA, 1976.

[2] W. S. Wingert, "GC-MS analysis of diamondoid hydrocarbons in Smackover petroleums," Fuel, vol. 71, no. 1, pp. 37-43, 1992.

[3] G. A. Mansoori, P. D. Araujo, and E. D. Araujo, Diamondoid Molecules: With Applications in Biomedicine, Materials Science, Nanotechnology \& Petroleum Science, World Scientific, Singapore, 2012.

[4] S. Landa and V. Machácek, "Sur l'adamantane, nouvel hydrocarbure extraitdu naphte," Collection of Czechoslovak Chemical Communications, vol. 5, no. 1, pp. 1-5, 1933.

[5] P. D. Araujo, G. A. Mansoori, and E. D. Araujo, "Diamondoids: a review paper-occurrence in fossil fuels, applications in petroleum exploration and fouling in petroleum production," International Journal of Oil, Gas and Coal Technology, vol. 5, no. 4, pp. 316-367, 2012.

[6] G. Ali Mansoori, "Diamondoid molecules," Advances in Chemical Physics, vol. 136, pp. 207-258, 2007.

[7] G. Galli, "Structure, stability and electronic properties of nanodiamonds," in Computer-Based Modeling of Novel Carbon Systems and Their Properties, L. A. Fasolino, Ed., vol. 3, pp. 3756, Springer, Colombo, Sri Lanka, 2010.

[8] G. A. Mansoori, "A unified perspective on the phase behaviour of petroleum fluids," International Journal of Oil, Gas and Coal Technology, vol. 2, no. 2, Article ID 24884, pp. 141-167, 2009.

[9] J. Chen, J. Fu, G. Sheng, D. Liu, and J. Zhang, "Diamondoid hydrocarbon ratios: Novel maturity indices for highly mature crude oils," Organic Geochemistry, vol. 25, no. 3-4, pp. 179-190, 1996.

[10] J. Chen, G. Logan, and R. E. Summons, "Application of diamondoid hydrocarbons to maturity assessment of the oils from Western Australia," Australian Petroleum Production \& Exploration Association Journal, vol. 38, no. 1, pp. 866-868, 1998.

[11] K. Grice, R. Alexander, and R. I. Kagi, "Diamondoid hydrocarbon ratios as indicators of biodegradation in Australian crude oils," Organic Geochemistry, vol. 31, no. 1, pp. 67-73, 2000.

[12] J. E. Dahl, J. M. Moldowan, K. E. Peters et al., "Diamondoid hydrocarbons as indicators of natural oil cracking," Nature, vol. 399, no. 6731, pp. 54-57, 1999.
[13] Z. Wei, J. M. Moldowan, S. Zhang et al., "Diamondoid hydrocarbons as a molecular proxy for thermal maturity and oil cracking: geochemical models from hydrous pyrolysis," Organic Geochemistry, vol. 38, no. 2, pp. 227-249, 2007.

[14] S. A. Stout and G. S. Douglas, "Diamondoid hydrocarbonsapplication in the chemical fingerprinting of natural gas condensate and gasoline," Environmental Forensics, vol. 5, no. 4, pp. 225-235, 2004.

[15] R. Sassen and P. Post, "Enrichment of diamondoids and 13C in condensate from Hudson Canyon, US Atlantic," Organic Geochemistry, vol. 39, no. 1, pp. 147-151, 2008.

[16] M. I. Jalees, T. S. Bianchi, R. Sassen, and F. Tahira, "Diamondoids and biomarkers: as a tool to better define the effects of thermal cracking and microbial oxidation on oils/condensates from reservoirs of the Upper Indus Basin, Pakistan," Carbonates and Evaporites, vol. 26, no. 2, pp. 155-165, 2011.

[17] L. Jinggui, P. Philp, and C. Mingzhong, "Methyl diamantane index (MDI) as a maturity parameter for Lower Palaeozoic carbonate rocks at high maturity and overmaturity," Organic Geochemistry, vol. 31, no. 4, pp. 267-272, 2000.

[18] Q. Liang, Y. Xiong, C. Fang, and Y. Li, "Quantitative analysis of diamondoids in crude oils using gas chromatography-triple quadrupole mass spectrometry," Organic Geochemistry, vol. 43, pp. 83-91, 2012.

[19] S. Li, S. Hu, J. Cao, M. Wu, and D. Zhang, "Diamondoid characterization in condensate by comprehensive two-dimensional gas chromatography with time-of-flight mass spectrometry: the junggar basin of northwest china," International Journal of Molecular Sciences, vol. 13, no. 9, pp. 11399-11410, 2012.

[20] C. J. Wandrey, B. E. Law, and H. A. Shah, "Sembar Goru/Ghazij composite total petroleum system, Indus and Sulaiman-Kirthar geologic provinces, Pakistan and India," in Petroleum Systems and Related Geologic Studies in Region 8, South Asia, C. J. Wandrey, Ed., U.S. Geological Survey Bulletin, 2004.

[21] V.-U. Quadri and S. M. Shuaib, "Hydrocarbon prospects of southern Indus basin, Pakistan," American Association of Petroleum Geologists Bulletin, vol. 70, no. 6, pp. 730-747, 1986.

[22] N. A. Zaigham and K. A. Mallick, "Prospect of hydrocarbon associated with fossil-rift structures of the southern Indus basin, Pakistan," AAPG Bulletin, vol. 84, no. 11, pp. 1833-1848, 2000.

[23] W. A. Pryor and J. D. Boer, Basin Classification and Assessment in Pakistan, Oil and Gas Development Corporation Internal Report, 1981.

[24] A.S.T.M. Standard Test Method for Pour Point of Crude Oils, 05. 02, D5853, 2010.

[25] A.S.T.M. Standard Test Method for Density, Relative Density, or API Gravity of Crude Petroleum and Liquid Petroleum Products by Hydrometer Method, 05. 01, D1298, 2012.

[26] A.S.T.M. Standard Test Method for Trace Quantities of Sulfur in Light Liquid Petroleum Hydrocarbons by Oxidative Microcoulometry, 05. 01, D3120, 2008.

[27] T. Fazeelat and A. Saleem, "GC-FID analysis of wax paraffins from Khaskheli crude oil," Journal of the Chemical Society of Pakistan, vol. 29, no. 5, pp. 492-499, 2007.

[28] R. Alexander, R. I. Kagi, R. Noble, and J. K. Volkman, "Identification of some bicyclic alkanes in petroleum," Organic Geochemistry, vol. 6, no. 1, pp. 63-72, 1984.

[29] B. P. Tissot and D. H. Welte, Petroleum Formation and Occurrence, Springer, 1984.

[30] E. S. Scalan and J. E. Smith, "An improved measure of the oddeven predominance in the normal alkanes of sediment extracts 
and petroleum," Geochimica et Cosmochimica Acta, vol. 34, no. 5, pp. 611-620, 1970.

[31] B. M. Didyk, B. R. T. Simoneit, S. C. Brassell, and G. Eglinton, "Organic geochemical indicators of palaeoenvironmental conditions of sedimentation," Nature, vol. 272, no. 5650, pp. 216222, 1978.

[32] H. L. Ten Haven, J. W. De Leeuw, J. Rullkötter, and J. S. S. Damsté, "Restricted utility of the pristane/phytane ratio as a palaeoenvironmental indicator," Nature, vol. 330, no. 6149, pp. 641-643, 1987.

[33] J. K. Volkman and J. R. Maxwell, "Acyclic isoprenids as biological markers," in Biological Markers in the Sedimentary Record, R. B. Johns, Ed., pp. 1-42, Elsevier, New York, NY, USA, 1986.

[34] W. B. Hughes, A. G. Holba, and L. I. P. Dzou, "The ratios of dibenzothiophene to phenanthrene and pristane to phytane as indicators of depositional environment and lithology of petroleum source rocks," Geochimica et Cosmochimica Acta, vol. 59, no. 17, pp. 3581-3598, 1995.

[35] G. Shanmugam, "Significance of coniferous rain forests and related organic matter in generating commercial quantities of oil, Gippsland Basin, Australia," American Association of Petroleum Geologists Bulletin, vol. 69, no. 8, pp. 1241-1254, 1985.

[36] J. Connan and A. M. Cassou, "Properties of gases and petroleum liquids derived from terrestrial kerogen at various maturation levels," Geochimica et Cosmochimica Acta, vol. 44, no. 1, pp. 123, 1980.

[37] S. C. Talukdar, B. De Toni, F. Marcano, J. Sweeney, and A. Rangel, "Upper cretaceous source rocks of Northern South America," American Association of Petroleum Geologists, vol. 77, no. 2, p. 351, 1993.

[38] R. Lin and Z. A. Wilk, "Natural occurrence of tetramantane $\left(\mathrm{C}_{22} \mathrm{H}_{28}\right)$, pentamantane $\left(\mathrm{C}_{26} \mathrm{H}_{32}\right)$ and hexamantane $\left(\mathrm{C}_{30} \mathrm{H}_{36}\right)$ in a deep petroleum reservoir," Fuel, vol. 74, no. 10, pp. 1512$1521,1995$. 

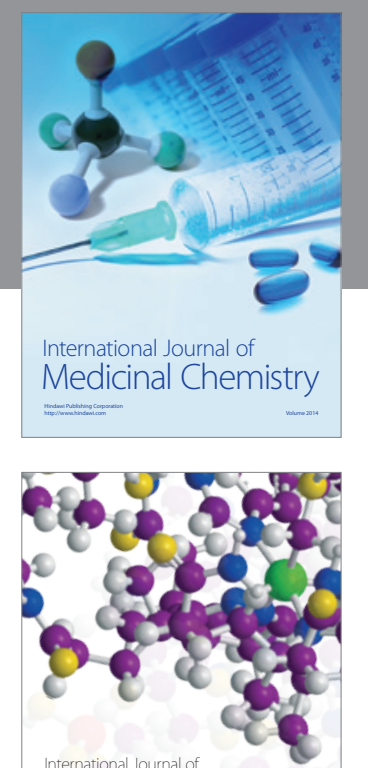

\section{Carbohydrate} Chemistry

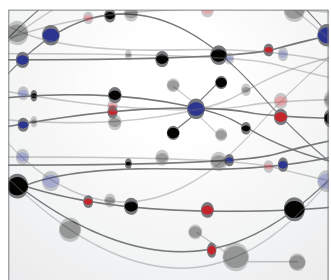

The Scientific World Journal
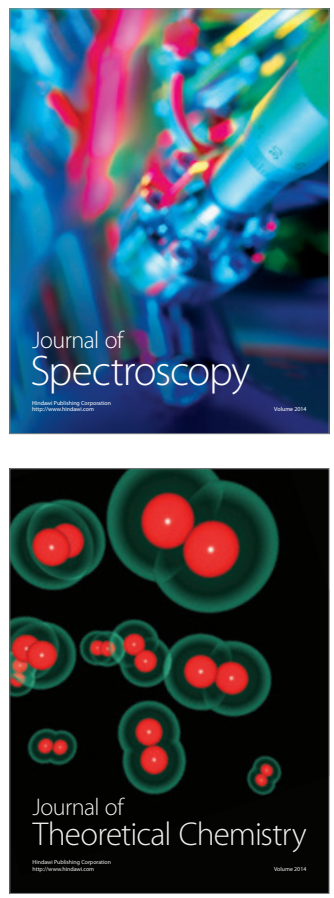
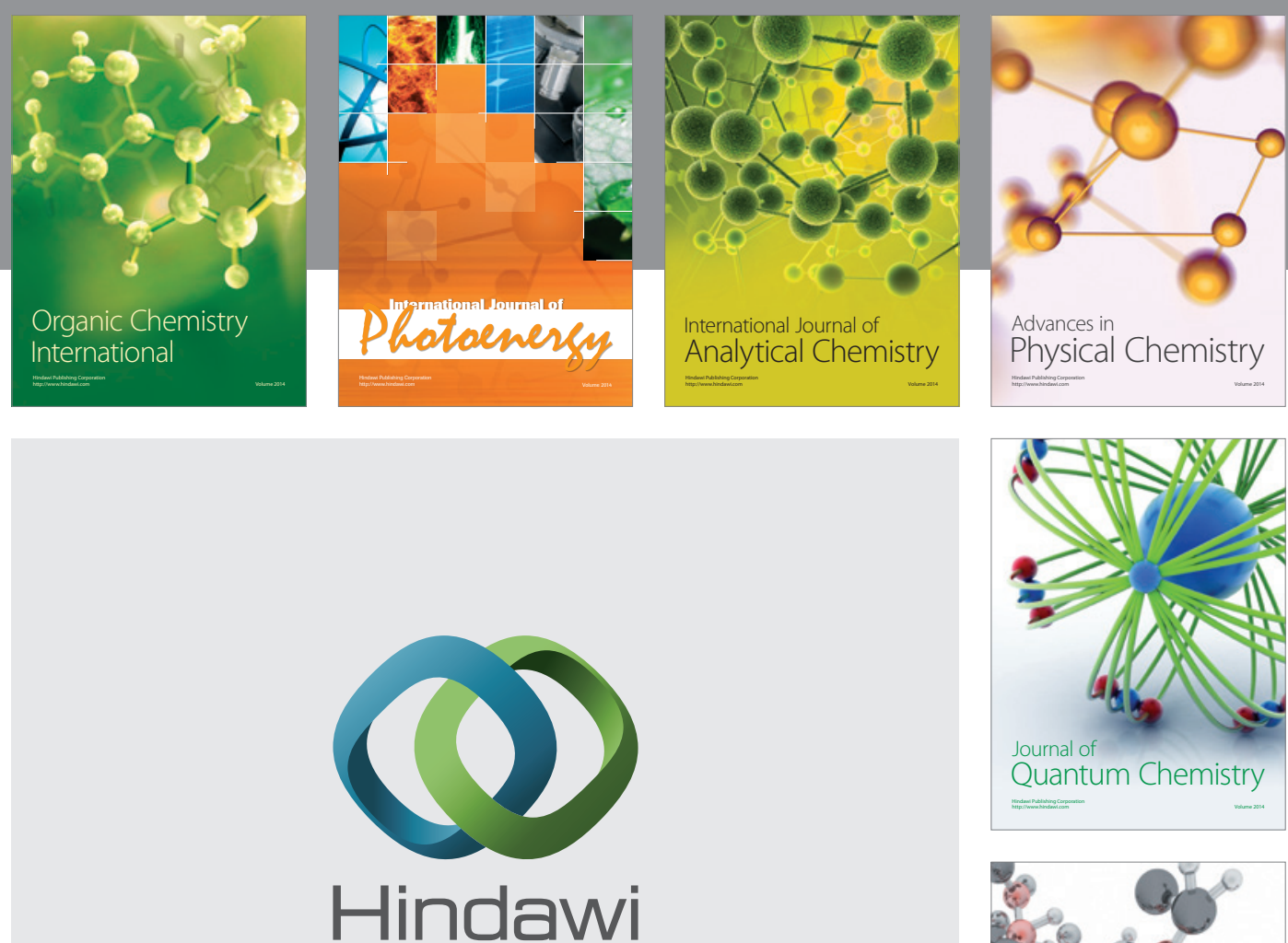

Submit your manuscripts at

http://www.hindawi.com

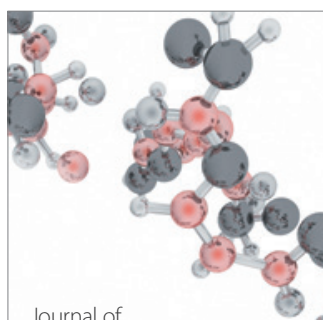

Analytical Methods

in Chemistry

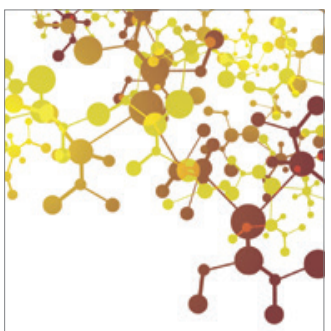

Journal of

Applied Chemistry

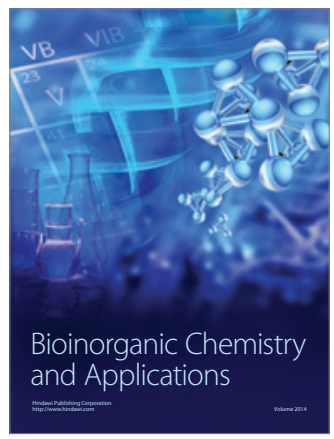

Inorganic Chemistry
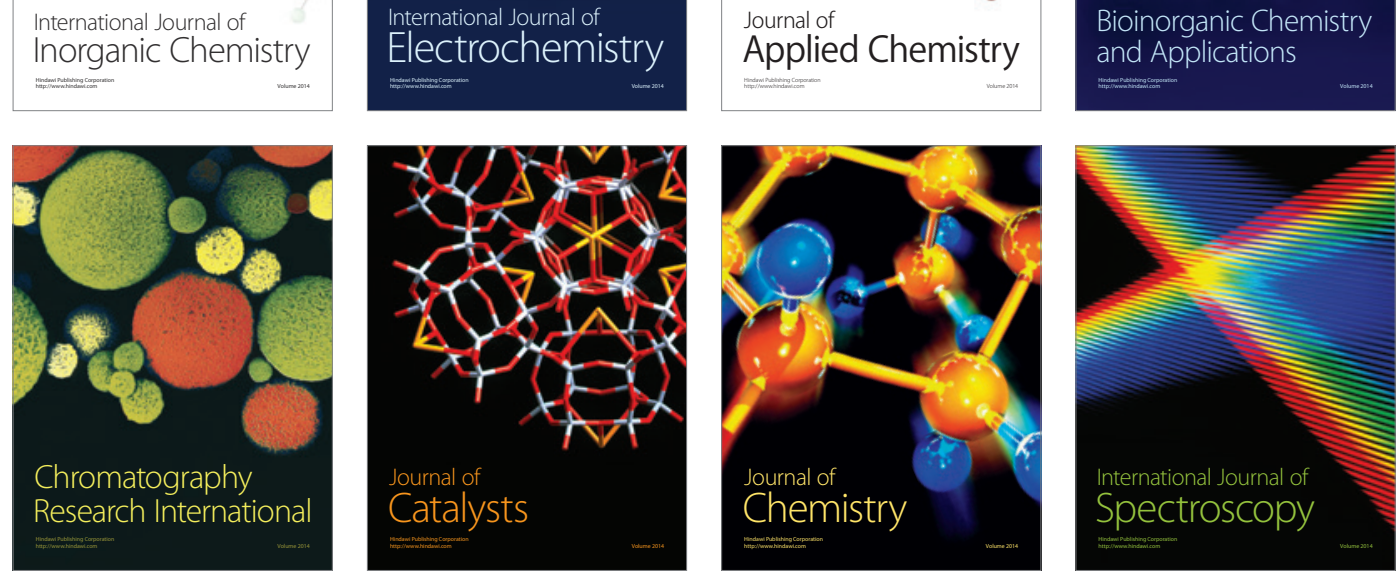